\title{
Materialism And The Locus Of The Subject Of Experiences
}

\author{
Thomas W. Smythe, PhD \\ Retired Associate Professor of Philosophy, \\ North Carolina Central University
}

doi: 10.19044/esj.2016.v12n5p1 URL:http://dx.doi.org/10.19044/esj.2016.v12n5p1

\begin{abstract}
The paper treats alternative views about a materialist conception of the subject of experiences or the self or person. Some views are that the self is the brain, or the whole person, or that there is no self or subject of experiences. We lay out each view and their advantages and disadvantages.
\end{abstract}

Keywords: Subject of Experiences, Self, Person, Brain, Body

There is a long tradition in philosophy, beginning wih ancient philosophers, about the nature of the self, soul, spirit, mind or subject of mental states or experiences. Many of these of these views were expounded by dualists on the nature of a person. One popular form of dualism is that a person is a combination of two substances, a mental substance and a material substance. Both the mental substance and the physical substance can exist independently of each other. The mental substance can exist without the body as a disembodied mind, and the physical substance or body can exist without the mind. There are other versions of dualism, and they all hold that our psychology or mental states are nonphysical or immaterial in nature. This paper considers what a materialist can say about the nature of a person or self as a subject of experiences.

To begin we will say what we are including under "materialism." One view of materialism is known as the Identity Theory (IT). The IT is based on the belief that the mind is the brain. A person's mental states are identical with the firings of particular neurons, or cells, in the brain. Pain, for example, is a neurological state. Other mental states are neurological states, even if we do not yet know what they are. The IT comes in different forms, but we are interested only in what the IT takes the subject of experiences to be.

Another current kind of materialism is known as Functionalism. The core idea of Functionalism is that mental states are neurological states of a physical system that serve the same functions as the neuron firings serve 
when we are in that mental state. The functions of neuron firings of mental states are spelled out in terms of environmental inputs, behavioral outputs, and relations to other mental states. Functionalism has joined the IT as a leading theory of the mind. This view impies that any complex system can have a mind and that the physical composition of the system does not matter.

The human is made of flesh and blood, but this is not essential. We could be made of other stuff, like aliens, and still be "thinking beings." We could even be made of silicon chips, like computers.

For this reason, researchers in artificial intelligence are attracted to Functionalism. The functionalist holds that the mind can be seen as a type of digital computer. The relation between body and mind is like the relation between hardware and software in a computer. A computer accepts inputs, performs operations on them, and produces outputs. The human brain works in the same way. The mind is simply a program running in the brain like the software of the computer. Although Functionalism is logically compatible with dualism and nonphysical mental states, most hold that mental states ae realized in the brain and central nervous system. We shall take the IT and Functionalism to be what we are calling materialism.

We will now deal with the problem of this paper. Just what physical aspects or thing would a materialist point to as being the subject of experiences or mental states? It is not clear that this question admits of any single answer, so we will do no more than lay out what seems to be some plausible alternatives and their difficulties.

The question is partly an empirical question. The location of the "subject" surely must depend on where we find mental states of events. Many proponents of IT, most notably J. J. C. Smart, maintain that "the verdict is overwhelmingly in favor of the brain" on the question of where we find mental states. ${ }^{1}$ If we have to choose between identifying mental properties with brain properties rather than properties of the heart or liver, then the location problem is an empirical one. Philosophers like Smart think that perceptions, sensations, images, thoughts, feelings, and all the elements that are "given" in conscious awareness, are, in fact, brain processes or states. If the mental elements or "given" are actually physical processes in the brain, it is a short step to make the perceiving self or subject of experiences identical with the brain. This is not to say that a person is, in fact, his brain because the concept of a person is only partly a subject of experiences. A person is just as much his entire body, even if the subject of experiences is the brain, since a person is also a subject of physical states in general. And although all mental states are physical states according to

1 J.J.C. Smartt, "Sensations and Brain Processes," Philosophical Review, Vol. 68, 1959, p. 46. 
materialism, there are physical states that are not also mental states. The terms involved in speaking of subjects of mental states and physical states are not synonymous, and it is at least an open question whether the subjects spoken of are coextensive.

Elsewhere, Smart attempts to bring out the fundamental role the brain and brain processes play in an adequate concept of mind. He compares behaviorists who deny the importance of inner physiological processes with instrumentalist views about the nature of thoretical entities in physics. Smart argues that we "can conceive of" a universe consisting of electrons, protons, and the like, that never come together as constituents of microscopic objects. He concludes that "on this supposition...there could be electrons...but no microscopic objects.",

Smart thinks mental states are analogous to electrons in this respect and argues that there is no clear sense in which (pain) experiences are grammatical fictions. He asks us to consider a future state of physiological technology where "we might be able to keep a human brain alive in vitro." By stimulating the brain with electrodes, we could give it the illusion of perceiving things, make it feel pain, arouse its desires, stimulate it to reason, and the like. Since this thought experiment is a case in which we would have mental experiences, but no behavior, Smart says, “This brings out vividly that what is important in psychology is what goes on in the central nervous system, not what goes on larynx, or limbs." This is supposed to show that there is a clear sense in which mental experiences are not grammatical fictions out of behavior, but they are "entities such as are postulated in a hypothesis (which) could still exist even if there had been no possible evidence for them." His preference for the brain as the locus of mental experiences, rather than the entire body, comes out when he concludes that "...the example of the brain in vitro shows that what is essential to a pain is what goes on in the brain, not what goes on in the arms or legs or larynx or mouth."3

It seems clear that nothing of this sort does follow about what is "essential" to thoughts and sensations. When Smart asks us to consider the brain in vitro, he is talking about what "could happen" and what we "can conceive of,” If we take him to be speaking of is merely logically possible, then, as Norman Malcolm points out, his "imagined case could not offer any evidence that the important for the existence of thoughts and sensations than outward behavior."4 In terms of the location problem, this thought

2 J.J.C. Smart, “Materialism,” Journal of Phil., Vol. 60, October, 1963, p. 659.

3 J.J.C. Smart, Ibid., p. 660.

4 Norman Malcolm, "Scientific Materialism and the Identity Theory," Journ. Of Phil., Vol. 60, 1963, p. 663. 
experiment does not show that the brain is more likely to be the locus of the subject of experiences than the entire body and its behavior.

If Smart were to suggest the view that there is a stong likelihood that the brain in vitro could

undergo all the mental states it was capable of in its embodied existence, then the question of the possible evidence would become stronger. In particular, in order to conclude that mental states are

most likely to be located in the brain, some of the problems that face the IT would have to be settled.

We would have to have more well established reliable psychophysical laws to the effect that a person has a mental state $M$ if he has a brain state $B$ at time $t$. We would also need a device for detecting the

presence of the relevant brain states. If so, the likelihood of a brain in vitro undergoing all the usual

mental experiences clearly presupposes that the location problem for mental events has already been solved, and therefore cannot be used as evidence for specifying the locus of the subject of experiences than the entire body and its behavior.

The literature on brains in a vat supports Smart's position. Consider the following. Imagine an advanced stage of science where we can remove a person's brain and keep it alive in a vat of nutrients. Scientists hook up the brain to a computer that supplies it with the kind of inputs that normally comes from the eyes and ears. If the computer does the job well enough, the person will believe is is actually perceiving physical objects. The person will have normal experiences, but his life will be a computer-generated ilusion. The question is raised of how you can prove this wrong. You can do nothing to prove you are not now a brain in a vat. This thought experiment seems to favor Smart's position.

We will now consider consider some difficulties in taking the brain as the subject of experiences.

There are two different kinds of considerations relevant to the location problem. One is the development of brain theory or neurophysiology. The other is less important in the end, but easier to make progress on, especially in philosophy. It involves the analysis of particular common sense psychological concepts insofar as they provide clues to the location of mental states.

Let us consider the development of science first. If science were to develop psychophysical correlation laws of the sort envisaged by the IT, the physicalistic variables of the laws would tell us a lot about the location of mental states. Although laws do not contain reference to space-time regions, the physicalistic variables may refer to specific types of neural processes going on in the brain, or the brain together with the entire central nervous 
system. At present we have only relatively crude and sketchy correlations between mental functions, such as memory, and gross areas of the brain. An ideal development would be to find out what part of the human body or brain and its states are present whenever mental states are, and absent whenever the relevant kind of mental states are, and this is no small task.

The description under which the mental and physical properties to be identified are placed in the correlation laws is also relevant to the location problem. In some forms of the IT, the features to be identified are described as "Jones thinking about $\mathrm{x}$ " and "Jones being in brain state B." In this case the location of the thought is specified by locating the individual Jones and no further. One writer construes the psychological term of the identity as "having a pain in the skin" and being in a certain physical state. The state of the body is located as precisely it can be by locating the whole body. ${ }^{5}$ Similarly, one is having a pain wherever his body happens to be. But this seems a bit evasive. Some mental states may have the entire body as their locus. Now if having a sensation is identical with having a brain process $B$, and B Has a particular location in the brain, then the sensation must have the same specific location. And it does seem we can say more about the location of neuron firings, chemical reactions, and electrical patterns than pointing to the individual to whom they occur.

What might be a plausible line to take on this alternative is to locate the "subject of consciousness" by locating the person. Although it is somewhat precipitous to decide that mental events have no more specific location than to the person they occur to, it might well be plausible to locate the subject of mental states where the individual of person is. It is precisely because a person is referred to be a sentence where ' $\mathrm{I}$ ' is used as a grammatical subject, and which employs both both psychological and physical predicates, that we say that a person is a "subject of experiences" at all. Jerome Shaffer has said that a person is defined as a subject of experiences. This would make it confusing to say that a person is just a human body, but the subject of experiences is the brain. For "person" and "subject of experiences" are connected analytically. If mental states are found to be mostly located in the body or parts of the body, it is reasonable to identify the subject of experience with the entire human body, and not just the human brain. Consider the emotion of fear. Fear is a disturbed or upset condition of the entire body. Its conative content is a tendency to avoid. The body grows tense, becomes stiff, causes the subject to sweat a lot, and one may be unable to move.

More recent literature in cognitive science supports the thesis that cognition is affected and located in the entire body. Alvin I. Goldman has 
supported the view that much of human cognition has its origins in the human body. He says that recent empirical findings in cognitive science lead one in this direction. This is known as embodied cognition. ${ }^{6}$

Here is a taste of some of the things Goldman and other cognitive theorists have said about mental states.

In another paper Goldman says "Many other systems are dedicated to other body-oriented topics. The primary somatosensory cortex is dedicated to representing the condition of (all parts of) the surface of the body. The so called pain matrix is a complex system consisting of two functionally specialized networks. The sensory discrimination component represents the intensity of pain and its bodily location. The affective component represents the unpleasantness of a painful experience. It recruits the anterior insula, the anterior singulate cortex, the thalamus, and the brain stem. In relatively recent work (Craig, 2002) a system of representation of the entire body that he calls“interoception” (a distinct species of inner sense). This system, the lamina I spinothalamocrtical system, conveys signals from small diameter primary afferents that represent the physiological status of all body tissues. Lamina I neurons project to the posterior part of the ventromedial nucleus or Vmpo. Craig calls the Vmpo "interoceptive cortex" and argues it contains representations of distinct, highly resolved sensations, including different types of pain, tickle, temperature, itch, muscular and visceral sensations, and sensory input."7

We might be well advised to drop any talk of "subjects of experience" at all. We speak of objects in the world that are referred to by grammatical subjects, such as physical things, yet we do not speak of subjects of physical states. We can speak of persons or human beings as having mental states, but we can do away with speaking of persons as "subjects" having mental states. If all we mean by a "subject having mental states" can be cashed out by simply speaking of a person or human being, we may well drop talk about subjects of consciousness. Then the only location question left will be where to locate the person who has the mental states, and we do that by locating their body.

There is a lot of literature on those who have denied that there is any

6 Alvin I. Goldman, “A Moderate Approach to Embodied Cognitive Science,” The Review of Philosophy and Psychology,

Vol. 3, No. 1, 2012, pp. 71-88. This article claims that cognition is "embodied" taking account of empirical evidence and contemporary cognitive science. Antonio Damasio supports Goldman in his Looking for Spinoza: Joy, Sorrow, and Feeling Pain,Orlando Fla., Harcourt, 2003. Esp. Ch. 3 on feelings.

$7 \quad$ Alvin I. Goldman, "The Bodily Format Approach to Embodied Cognition," Current Controversies in Philosophy or Mind, ed. by Uriah Kriegel, Routledge, 2014, p. 101. 
real self or subject of experiences. David Hume famously denied that he had any knowledge or perception of a self in his experience. He said he cannot form a sense impression or mental image of a self. The self is a fiction.

A J. Ayer made a similar move in the $20^{\text {th }}$ century along with other strict empiricists. He denied that we can have any sense perception of the self.

Sydney Shoemaker gave a definitive criticism of the empirical denials of the self based on sense perception. Shoemaker asks us to consider "I see a tree." This statement is true just in case there is a tree there, and I am looking at it, paying attention, and so on. I cannot come to realize that is I who am seeing the tree, because I cannot discover that there is a tree in my visual field and that I am not perceiving it. The tree cannot be given in experience at all unless it is given as my perception of the tree. I cannot perceive the tree, and perceive myself, and see that it is I who am in the relation of perceiving with the tree. For, if I could do that, it would have to be possible for me to perceive myself, and see the tree, and see that it was a fact about myself, that I am not perceiving the tree. Clearly this is not possible because the relation of perceiving is not an empirical, contingent relation. For the self and the object of perception are co-determinative; each is a necessary condition for the other. Thus it is self-contradictory to suppose that I could perceive a tree, and realize, as a fact about this perceptual relation, that it is not me perceiving the tree. But this should be possible if we are to account for self-awareness soley in terms of what is exclusively perceived by myself. 8

The notion of a subject is often introduced as an analysis of perceptual awareness. Awareness of something $\mathrm{x}$ is thought to involve a relation between something which is aware, a subject of awareness, and the object they are aware of. Perhaps a materialist should resist this analysis and eshew the use if the technical term "subject" since it does not do any work for us which cannot be done by speaking of a person or human being that which is aware of objects and is that which has experiences. We can avoid the solemn phrase "The Subject of Experiences" that fills chapter headings in books and dissertations, since it misleads us into looking for something that has experiences other than the person themselves, often something "inside" the person.

Probably the most important reason for disussions of a subject of experiences comes from the vast literature on self-awareness or selfknowledge of the mental. Considerations about how we know the self have influenced some philosophers who are dualists to say that the subject of

8 Sydney Shoemaker, Self-Knowledge and Self-Identity, Cornell University Press, Ch, 4, 1963. This is a fatal criticism to empricists who deny the existence of a self on perceptual grounds. 
experiences is a mental substance or thing that is nonphysical or immaterial in nature. I have argued elsewhere that self-awareness if the subject of mental states is actually awareness of a mental substance, but that substance could be realized in something physical. One can be aware of their mental states and self-aware of something that has the mental states. However, I contend that awareness of mental states does not inform us by itself on the nature of those mental states; on whether they are nonphysical or physical in nature. Similarly, awareness that I am a subject of mental states does not by itself tell the knower whether the self or subject is nonphysical or physical in nature. I am aware of myself as what is having mental states, and aware of a mental substance, but the nature of that substance is an open question. ${ }^{9}$ We will not plunge into a treatment of the literature on self-knowledge of the self here.

Let us now consider some ways in which our ordinary talk about minds and particular psychological concepts have a bearing on the location of mental states. Gilbert Ryle has pointed out that we say we are doing mental arithmetic 'in our head' rather than on paper, and where a man may say he still has a catchy tune or jingle 'running in his head.' This is about as far as we can go in common sense in locating mental events in the brain. Ryle argues that this sort of talk is highly metaporical since a surgeon could not open your brain and detect any calculation going on, or listening to the tune with a stethoscope the way a doctor listens to my heartbeat ${ }^{10}$. But the same point could be made for a computer. We could not detect it calculating by looking at the hardware or circuit boards. David M. Armstrong points out where we can speak of 'having brains' (an acute mind), and of a 'brain-child', 'brainstorm,' 'racking one's brain' and 'brainwashing' in connection with the mind. Other colloquialisms such as 'egghead' suggest a close connection between the brain and cognitive functions. Having a 'good mind' and a 'good head on your shoulders' are often used interchangably.

Yet there is a sense in which whatever we can say about the parts of the body we can often say about the whole body. We say of a car that 'the carburator isn't working properly' and we can also say 'the car isn't working properly.' We could say 'the door is rattling' instead of 'the car is rattling' when we want to be more specific. This suggests that the specification of the physical locus of the subject of experiences is partly a terminological matter. Even if mental events are identified with events in the brain, and the brain is designated as the subject of mental events, it is still possible to speak of the

9 Thomas W. Smythe, “Intuiting the Self,” Psychology of Intuition, edited by Bartoli Ruelas and Vanessa Briseno, Nova Science Publishers, September 2010. 
whole person, or the entire human body, as having or undergoing mental events. This is complicated even more by the fact that human beings are often construed as agents, and mental activities are often thought of as what the agent or entire physical organism is engaged in. Instead of saying the brain thinks when one is racking his brains, we say a man thinks with his brain. The brain is considered to be an instrument of thought or something we use to think with. But it still may be proper to specify some part of a man, such as the brain, as being that which has the mental states, or being that in which the mental states occur.

Our concepts of some mental states may preclude a specification of a particular locale for them at all. Richard Taylor hold that thoughts are not existing things or entities that exist in the head. He conceives of thinking as an activity we perform just like waltzing, playing chess, or solving algorithms with pencil and paper. Thinking might be seen as something we do 'in our heads' and not something that results in thoughts that are identical with brain states. ${ }^{11}$ Taylor's point is consistent with saying that thinking is an activity in the brain, and that the brain is where thinking is carried on, even though we can still say it is the human being or person that thinks. Given this conception of thinking, locating thinking as an activity will be quite different than locating a mental event called a thought. A thought can be viewed as an abstraction and as having no location. This example shows that the location problem depends on our view of particular mental concepts.

This completes the sketch of the way our mental concepts may influence the location problem. We do not take a stand on the problem here. We have focused on one strand of the problem: the locus of the subject of mental states. The purpose is to display some of the alternatives and difficulties involved. It should be clear that materialism does not depend on which alternative we adopt for its plausibility. Smart does not have to make the claims he does about the possibility of the brain having mental experiences in vitro in order to hold that mental goings on are brain processes. The truth of materialism is independent of which physical thing is the subject of experiences or of exactly where particular mental events and processes are located. A referee has asked whether a dualist can accept the brain in vitro example and maintain that the soul that is nonphysical and immaterial can be interacting with the brain. The materialist holds that disembodied minds are a logical possibility, but in fact the mental is identical with physical states of a subject or person. As I said, I have argued elsewhere that in self-awareness we are aware of ourselves as being something, as being a thing that is having mental experiences, but our self-awareness does not tell us anything about whether that something is physical or nonphysical 
in nature. We just cannot know that by looking within ourselves. The materialist holds that the self or subject is in fact something physical in nature. Dualism or an immaterial subject remains only a logical possibility.

Smart's suggestion that the brain may have mental experiences in vitro remains a focal issue for the outcome of the problem. For if a brain as such could have mental states without the rest of the body, there is a sense in which mental states or events are in, or states of, the brain and there is a clear way in which the brain is that part of a person that has mental states. And if the brain is the locus of mental states, it must be able to have mental experiences in vitro under some possible conditions.We conclude that if cognitive scientists and philosophers continue to locate mental states and events in states of the human body, it will be reasonable to locate the subject of mental states in the body and brain combined; in the whole embodied person. Dualists who think the location problem facing materialism is a good objection to materialism have been refuted by the empirical and theoretical developments in cognitive science.

\section{References:}

A. D. Craig, "What Do You Feel? Interoception: The Sense of the Physiological Nature of the Body,”Nature Review Neuroscience, 2002, Vol. 3 .

Antonio Domasio, Looking for Spinoza: Joy, Sorrow, and Feeling Pain, 2003, Orlando, Fl., Harcourt.

Alvin I. Goldman, “A Moderate Approach to Embodied Cognitive Science,” The Review of Philosophy and Psychology, 2012, Vo. 3,No. 1.

Alvin I. Goldman, “The Bodily Format Approach to Embodied Cognition,” Current Controversies in Philosophy of Mind, ed, by Uriah Kriegel, Routledge, 2014.

Norman Malcolm, "Scientific Materialsm and the Identity Theory," Dialogue, III, 1964.

Thomas Nagel, “Physicalism,” Philosopical Review, Vol. 74, July, 1964.

Gilbert Ryle, The Concept of Mind, Barnes and Noble, 1949.

Sydney Shoemaker, Self-Knowledge and Self-Identity, Cornell University Press, 1963.

J.J.C. Smart, “Sensations and Brain Processes.” Philosophical Review, Vol. 68, 1959.

J.J.C. Smart, “Materialism,” Journal of Philosophy, Vol. 63, October 1963.

Thomas W. Smythe, “Intuiting the Self,” Psychology of Intuition, ed. By Bartoli Ruelas and Vanessa Briseno, Nova Science Publishers, September 2010.

Richard Taylor, Action and Purpose, Prentice-Hall, 1966. 